\title{
Intracortical Dentate Fascia Grafts: Mossy Fiber Synapses in the Host Neocortex
}

\author{
Z.N. Zhuravleva and O.S. Vinogradova \\ Institute of Theoretical and Experimental Biophysics, Russian Academy of Sciences \\ Puschino-on-Oka, Moscow, 142 292, Russia
}

\section{SUMMARY}

Embryonic dentate fascia was grafted into a cavity in the area of the adult rat neocortex which represents the vibrissae (barrel field). We wished to test the possibility of development of connections between the two brain areas which do not have synaptic or tissue contacts in situ. The unique characteristics of the giant synaptic boutons of the dentate mossy fibers were used for detection of the dentate synaptic contacts with neocortical neurons at the electron microscopic level. Ultrastructural analysis nine months postgrafting has shown that the bundles of mossy axons enter the host neocortex and develop multiple terminal and en passant contacts with typical characteristics. Neuronal perikarya, large dendritic trunks and fine caliber terminal dendritic branches were used by the mossy fibers as postsynaptic targets, as well as spines of various complexity and configurations. The subsynaptic dendrites seemed to be modified by synapsing giant boutons. Accumulation of cytoplasmic organelles was observed at these sites. Various bumps and protuberances were formed by the subsynaptic dendrite surface. The contents of these appendages were variable; some of them contained organelles typical of dendroplasm, while others were more spine-like, often with inclusion of ribosomes. It is concluded that mossy fibers growing into the host neocortex can develop typical contacts with inappropriate targets with all the ultrastructural features of functional synapses.

\section{KEY WORDS}

giant synapses of dentate mossy fibers, ultrastructure, transplantation, neocortex, postsynaptic elements, modification, specificity of connections

\section{INTRODUCTION}

One of the important problems of the developmental and restorative plasticity of the brain is that of degree of specificity of connections established by growing or regenerating axons with neuronal targets. Neurotransplantation has been used as a method for evaluation of specificity of connections between the graft and host brain; however, the experimental data are still contradictory. While some authors demonstrate highly specific connections established by the grafted neurons which avoid inappropriate targets $133,42,53 /$, there is also evidence of atypical contacts, depending mainly upon the spatial proximity of the available targets $138,57 /$. As indicated by many authors, it is possible that biochemically specified brain areas with "diffuse", widespread connections (belonging either to the host brain or to the transplant) are more prone to regrowth and establishment of connections with unspecified targets, rather than specific, "point-topoint" systems 144,45/. However, unusual connections established by some specific structures of the brain (neocortex, cerebellum) have also been demonstrated in transplantation experiments $/ 9,38$, $39 \%$.

The purpose of the present work was to determine whether the mossy fibers of the dentate fascia establish synaptic connections with the surrounding host tissue after transplantation into rat somatosensory neocortex (barrel field). The mossy 
fiber system can be regarded as a highly selective one, establishing synaptic contacts with definite dendritic levels of the hippocampal regio inferior. The unique characteristics of the giant synapses of the mossy fibers can be used for their identification in the host neocortical tissue surrounding the graft.

\section{MATERIALS AND METHODS}

\section{Donor material}

The fetuses of Wistar rats, taken on the 20th day of gestation (E20), were used as donors. The hippocampal anlage was exposed by a parasagittal incision of a hemisphere $1 \mathrm{~mm}$ lateral to the midline. The dentate tissue was carefully dissected from the ventral ridge of the hippocampus. Precautions were taken to avoid the adjacent hippocampal tissue as far as possible. Approximate volume of the tissue taken for grafting was about 0.3 cubic $\mathrm{mm}$. The excised tissue was placed into cooled Eagle medium.

\section{Preparation of the recipients}

Young adult ( 3 months) male Wistar rats $(n=11)$ were used as recipients. Under Nembutal (40 $\mathrm{mg} / \mathrm{kg}$, i.p.) and local Novocaine anesthesia a small trephine opening was made in the skull. The dura was incised over the barrel field of the primary somatosensory neocortex $(\mathrm{AP}=+2.0 ; \mathrm{L}=5.5)$. A small volume of gray matter ( 1 cubic $\mathrm{mm}$ ) was aspirated through a slit in the dura using a syringe with an attached glass capillary tube. The trephine opening was then closed and the scalp sutured. The recipients were allowed to survive for nine months.

\section{Electron microscopy}

The animals were given injections of heparin ( 2500 units in $0.5 \mathrm{ml}$, i.p.), and were then perfused intracardially, first by oxygen-saturated saline, and second by a $2.5 \%$ solution of glutaraldehyde with $0.1 \mathrm{M}$ phosphate buffer at $\mathrm{pH} 7.2$ for $30 \mathrm{~min}$. Next the brains were removed and placed in the same solution for additional fixation. The neocortical slabs containing the dentate grafts were dissected under a stereomicroscope. The tissue samples taken for investigation were rinsed in phosphate buffer, postfixed in $1 \%$ osmium tetroxide, dehydrated in ethanol of increasing concentrations and absolute acetone, and embedded in Epon 812 .

Semi-thin sections, stained by methylene blue, or soaked in vaseline oil, were used for orientation and selection of the areas for further analysis (see /56/). For the purposes of the present experiments the areas of the host neocortex adjacent to the graft (0.3-0.5 mm) were selected. To avoid any mistakes in identification of the cellular elements as belonging to donor or recipient, only areas of the neocortex separated from the graft by a definite glial interface were selected for analysis. Ultrathin sections of these areas were contrasted by standard methods (uranyl acetate and lead citrate) and analyzed under a Tesla BS 513 electron microscope.

\section{Criteria for identification of the mossy fiber synapses}

A short description of the mossy fiber synapses, based on the data of many authors $/ 5,21,24,26,36 /$ including our own observations $/ 55 /$, is necessary to show the criteria used for identification of these synapses in the neocortical tissue surrounding the transplanted dentate fascia. It has been shown that the bundles of thin (diameter 0.2-0.3 $\mu \mathrm{m}$ ) unmyelinated axons of the dentate granule cells (mossy fibers) have terminal synapses which are among the largest in the CNS (diameter 4-6 $\mu \mathrm{m}$ ). They are characterized by a very high content of densely packed, small, clear, round vesicles. Larger dense-core vesicles are usually present among them. The synaptic bouton also contains several mitochondria. The terminal giant synapses, as a rule, contact large ramified dendritic spines (excrescences) on the proximal part of the apical dendrites of CA3 large pyramidal cells (stratum lucidum). The multiple active zones of a single giant synapse sometimes contact the spines of different adjacent pyramidal neurons and are asymmetric (Gray I). Besides the giant terminal contacts, the mossy fibers make contacts "en passant" with hilus cells, dendritic shafts of the $\mathrm{CA} 3$ pyramidal neurons, and also with spineless dendrites of pyramidal basket cells $/ 16,17,50 /$. Smaller terminal synapses are also made by mossy fiber collaterals, as shown recently $/ 10 \%$. The peripherally cut parts of irregularly shaped giant synapses, as well as smaller synaptic boutons on dendrites and usual types of 
spines, can be identified as belonging to the mossy fibers on the basis of their vesicular content, especially if they are observed in the vicinity of giant synaptic profiles, or can be traced to the parent mossy axon. Besides the typical active zones the mossy fiber synapses usually have desmosome-like contacts with the dendritic surfaces, characterized by prominent symmetric thickenings of the apposing membranes.

These unique ultrastructural features were used in the present work to search for and identify mossy fiber synapses in the host neocortex after dentate fascia transplantation.

\section{RESULTS}

Investigating the interface between the dentate fascia grafts and host neocortex, we have previously shown $/ 56 /$ that the border areas, constituted by accumulation of glial cells and their processes, are penetrated by numerous axons, some dendrites and accompanying astrocytic processes. Among the axons growing into the host neocortex, dense bundles of thin unmyelinated processes, as well as single axons with the characteristics of mossy fibers, were conspicuous. The narrow (intervaricose) parts of these axons contained longitudinally oriented microtubules. Their varicose expansions also contained clear synaptic vesicles, whose density increased near the sites of synaptic contacts made en passant. The parallel course of such bundles, which is typical for normal hippocampus, usually cannot be traced in the host brain for any considerable distance, because of its tortuous route among the elements of the neocortex.

However, in some cases such mossy-like fibers could be seen terminating with typical giant boutons. At low levels of magnification the giant mossy fiber synapses dispersed in the host neocortical tissue were easily identified. Their distribution in the investigated area was relatively homogeneous, without areas of accumulation or regions free of these synapses. Nor was a gradient of their density with increasing distance from the graft found in the area examined. Though the aberrant giant terminal synapses were relatively often encountered in the host neocortex, they constituted only a limited proportion of the total amount of synaptic terminals. Solitary profiles of the giant synapses could be observed in some cases, but more often they were grouped in small clusters around some neuronal somata or dendritic trunks. Such clusters usually consisted of 3 to 6 giant axonal expansions, and also included several smaller boutons $(1-2 \mu \mathrm{m})$. Some of them could be identified as peripherally cut parts of giant synaptic bags of complex ramified configurations on the basis of identical inner ultrastructure. In some cases it was possible to see that different presynaptic profiles represented expansions of a single mossy fiber.

Giant synaptic boutons detected in the neocortex often had very complex configurations, densely packed with lucid round synaptic vesicles, and with the usual admixture of dense-core vesicles. The growth vesicles were also present in some preterminal mossy fibers and their boutons. It is notable that the boutons, containing a significant number of the growth vesicles, were usually clustered together. Several mitochondria were always present in the giant boutons; up to $10-15$ mitochondria could be found in a single terminal. However, at least some of them seemed to represent fragments cut off a single mitochondrion of complex configuration (Fig. 1A). Bundles of thin unmyelinated mossy-like fibers were often present in their vicinity, encircling and even penetrating some giant synapses (Fig. 1B).

The postsynaptic elements, contacted by giant synapses growing into the host neocortex, were very variable. The typical asymmetric synapses with accumulations of vesicles on the presynaptic sides could be observed directly contacting neuronal perikarya and large dendritic trunks (Figs. 1,2). In such cases it was sometimes possible to detect that the postsynaptic cells were represented mainly by neocortical pyramidal neurons and their apical dendrites. However, giant synapses were also present on more distal levels of dendritic shafts, areas of their branching and on thin peripheral dendritic branches (Fig. 3).

The mossy fibers not only contacted the neuronal somata (Fig. 2A), but sometimes were deeply invaginated into neuronal cytoplasm. Transversely cut single mossy fibers, and whole bundles of mossy fibers with multiple contacts en passant, as well as terminal boutons, could be seen 


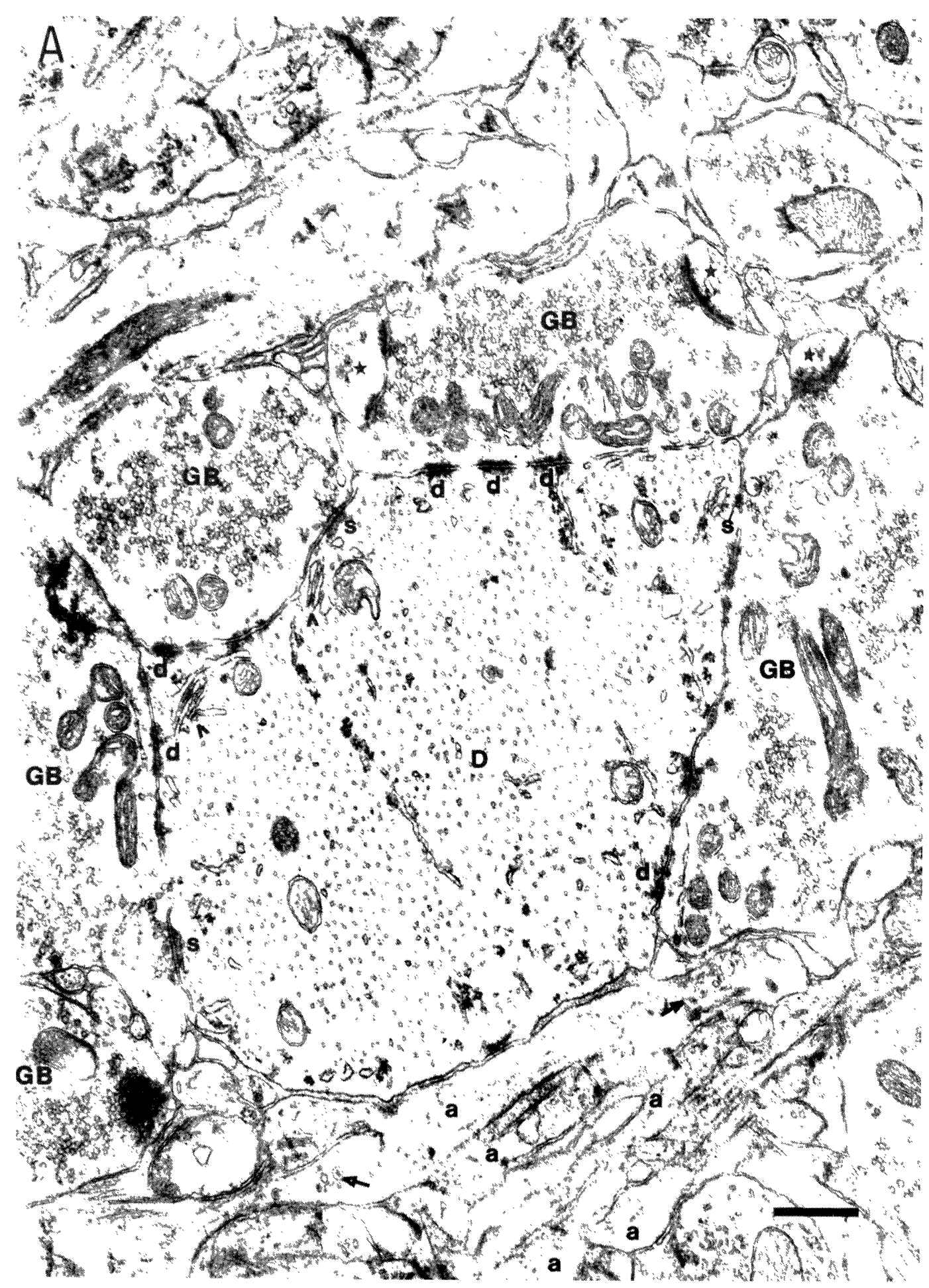

Fig. 1: Mossy fibers and their giant synaptic boutons (GB) in the host neocortex. A. A cluster of GB making chemical synaptic contacts (s) and desmosome-like contacts (d) upon the surface of a large dendritic trunk (D). Several synaptic contacts are seen on round or olive-shaped dendritic spines (asterisks). Arrowheads mark stacks of cisterns of agranular reticulum in the dendroplasm, resembling spine apparatus. Note accumulation of mitochondria in synaptoplasm adjacent to desmosome-like contacts. A bundle of thin unmyclinated mossy-like axons (a) is seen at the right lower part of the microphotograph. Accumulations of vesicles (arrows) are present in some of these axons. Bar $0.5 \mathrm{~mm}$. 


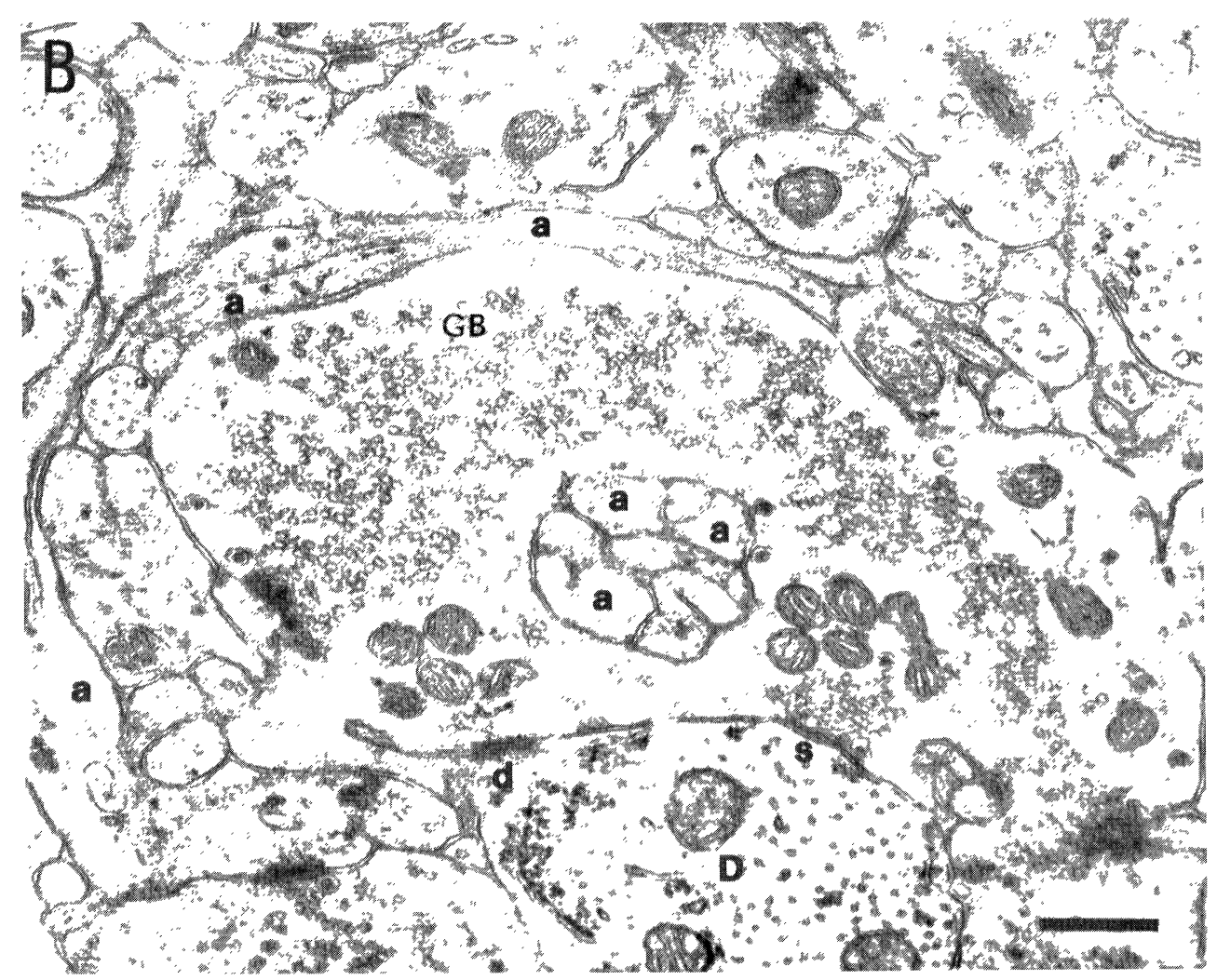

Fig. 1B: Giant synapse partly surrounded and penetrated by a bundle of mossy-like fibers. All indications as in Fig. 1A. Bar 0.5 $\mathrm{mm}$.

completely surrounded by neuronal cytoplasm (Fig. 2B).

Though in many cases the dendrites contacted by giant synapses had a usual, undisturbed structure, at times the subsynaptic areas appeared modified. Some dendritic branches contacted by giant boutons contained numerous cytoplasmic organelles, such as polyribosomes, mitochondria, multivesicular bodies and single cisterns of agranular endoplasmic reticulum, though normally dendrites of such caliber contain mainly (or only) neurotubules (Figs. 3A, 5B). Some mossy fiber synapses contacted the growing tips of small (terminal) dendritic branches, which contained groups of cisterns of rough endoplasmic reticulum (Fig. 3B). Large protuberances were occasionally present on the dendrites contacted by giant boutons. These protrusions contained cytoplasmic organelles (Fig. 4A,B) and also had variable and complex configurations. The larger and more complex protrusions had more abundant and variable contents.

Giant boutons also established multiple synaptic contacts with dendritic spines of variable shapes: small and round or olive-shaped buds on the dendritic surfaces as well as simple slender spines characteristic of neocortical neurons (Fig. 1A). However, relatively large branched excrescences, resembling those in the hippocampal stratum lucidum, were found on some neurons identified as pyramidal cells (Fig. 5B). The heads of such dendritic spines contained flocculent material with membranous and vacuolar inclusions. The typical spine apparatus was seldom observed in them, and, if present, its cisterns were not usually organized into an ordered structure.

Besides the typical asymmetric chemical synapses, the giant boutons also made contacts of another type. These were desmosome-like contacts with symmetric electron-dense thickenings on both 


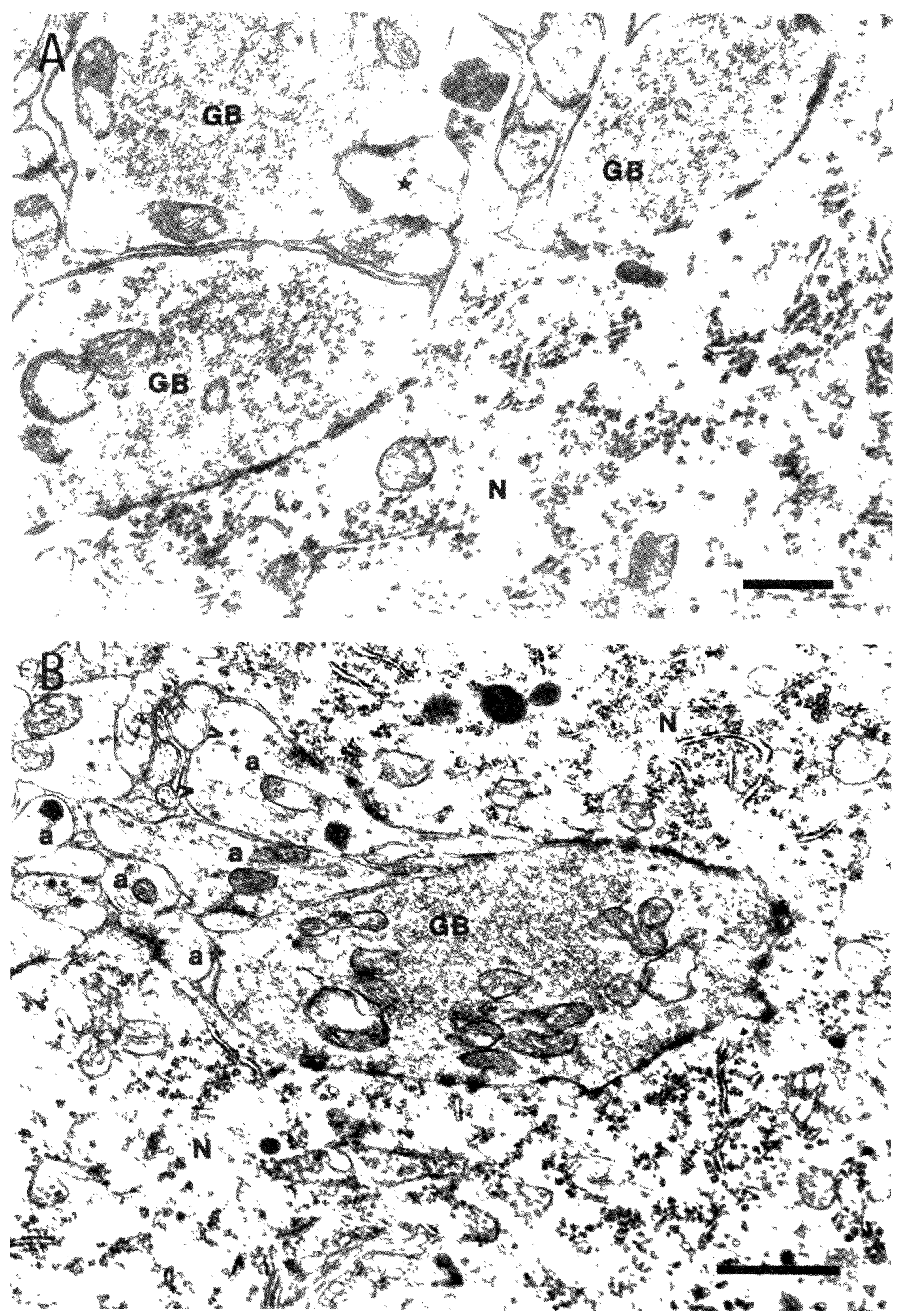

Fig. 2: Perikarya of the neocortical ncurons (N) as postsynaptic targets for the ingrowing mossy fibcrs. A. A cluster of giant synaptic boutons (GB) making multiple synaptic contacts with the somatic membrane and with a somatic spine (asterisk), the head of which contains flocculent material, typical of dendritic spines. Bar $0.5 \mathrm{~mm}$. B. A bundle of mossy fibers, decply invaginating into neuronal cytoplasm, with a terminal giant synapse (GB) and multiple contacts en passant with the perikaryon membranc. Besides the usual vesicles, a few growth vesicles (arrowheads) are present in some axons (a). Bar $1.0 \mathrm{~mm}$. 


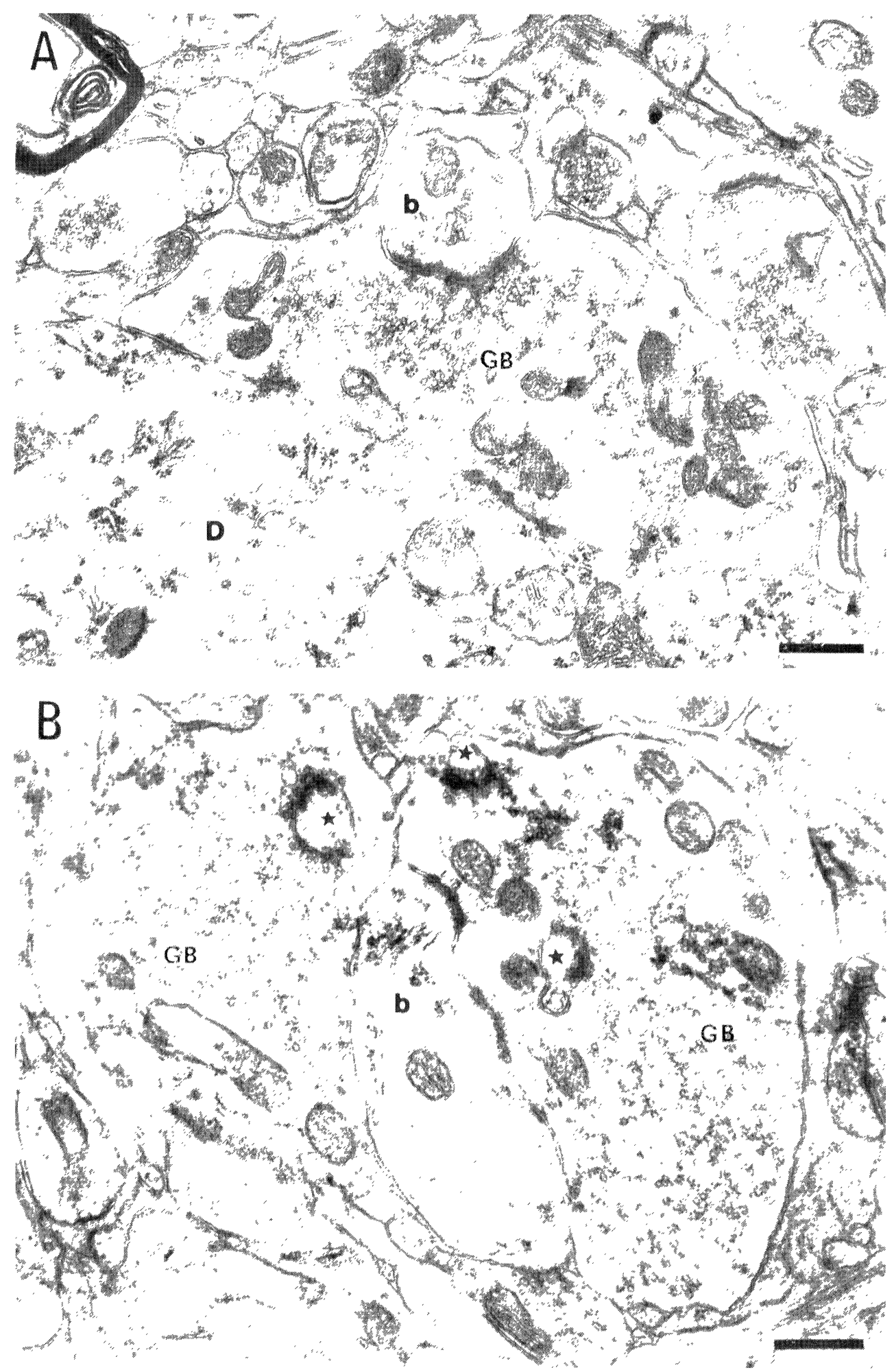

Fig. 3: Dendrites of varying caliber as targets of ingrowing mossy fibers. A. Giant bouton (GB), with chemical contacts upon both a large dendritic trunk (D) and a thin dendritic branchlet (b). Bar $0.5 \mathrm{~mm}$. B. Two giant synapses (GB) encircling a thin dendritic branchlet (b). Profiles of invaginated dendritic spines (asterisks) with synaptic contacts are present in the synapses. Elements of agranular (in A) and granular (in B) endoplasmic reticulum can be seen in the dendritic branches. Bar $0.5 \mathrm{~mm}$. 

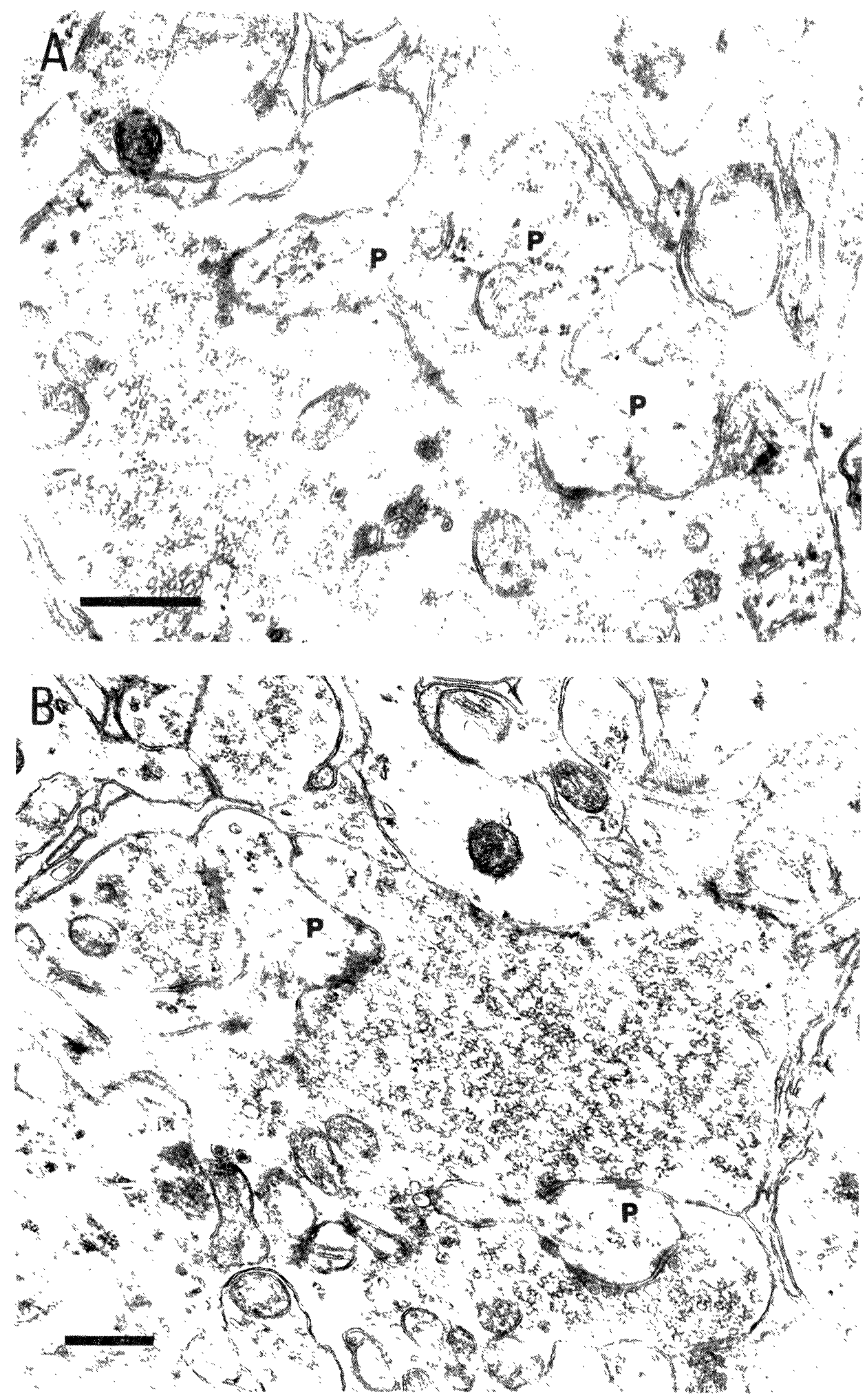

Fig. 4: Dendritic protuberances of complex shape and with various contents contacted by the giant synaptic boutons. A. Protuberances ( $p$ ) with contents characteristic of dendroplasm. Bar $0.5 \mathrm{~mm}$. B. Dendritic protuberances $(p)$, which have spine-like contents, but also include ribosomes (see the upper one). Bar $0.5 \mathrm{~mm}$. 

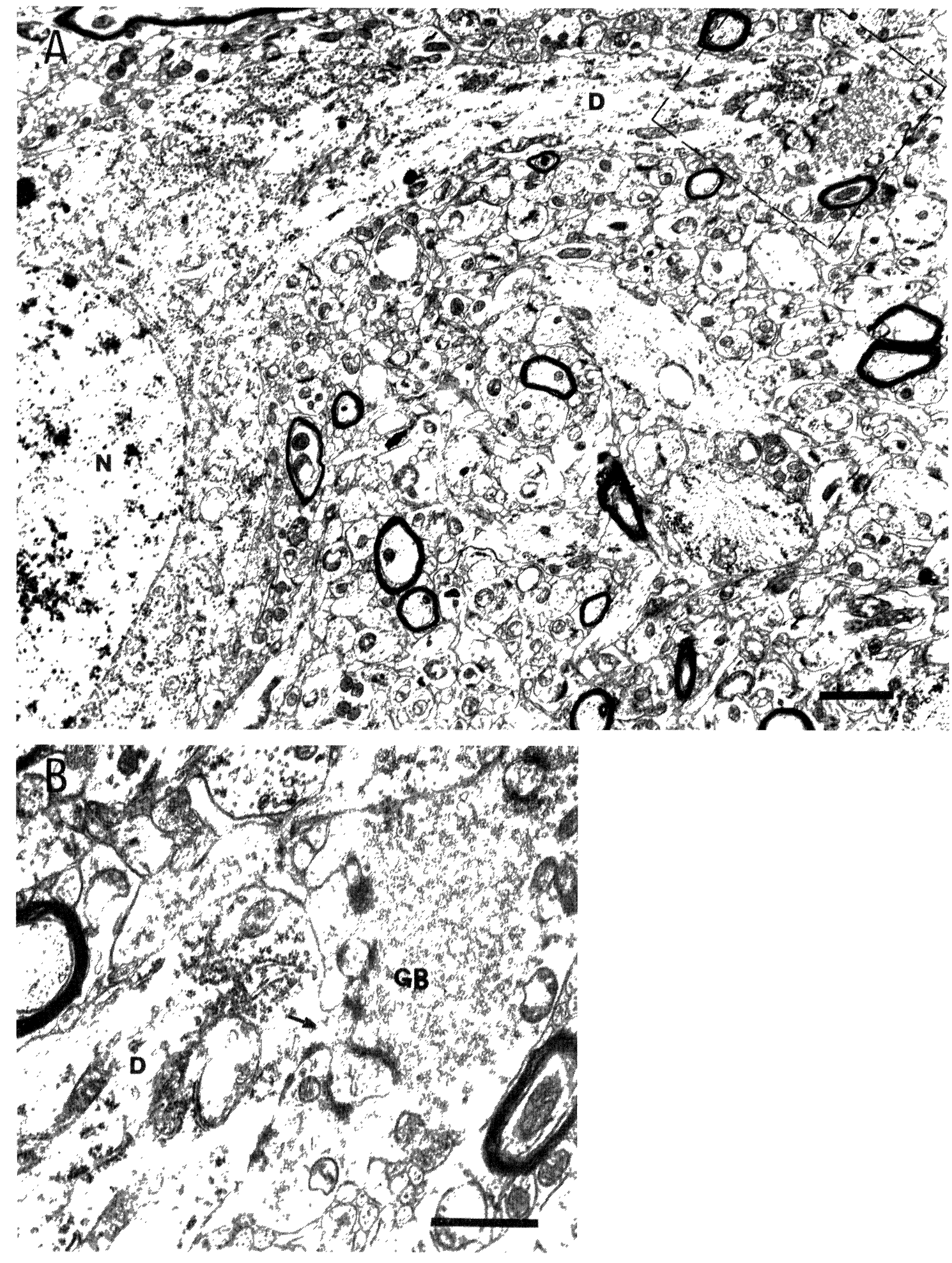

Fig. 5: Axo-spinous giant synapse on the apical dendrite of a neocortical pyramidal cell. A. General view, permitting the identification of the pyramidal neuron $(\mathrm{N})$ with its apical dendritc (D). The area in the box is shown in $\mathbf{B}$ at higher magnification. Bar $2.0 \mathrm{~mm}$. B. The branched spine on the dendrite, contacted by a giant bouton (GB). Arrow indicates the place of outgrowth of the spine from the parent dendrite. The area of the dendrite adjacent to the GB contains accumulations of cisterns of granular endoplasmic reticulum. Bar $1.0 \mathrm{~mm}$. 
sides. They were usually present on dendritic shafts and perikarya. Accumulation of synaptic vesicles was never present in areas of such contacts. However, clusters of mitochondria in the adjacent synaptoplasm was typical of them (Figs. 1A,3B). Unitary elements of granular or agranular endoplasmic reticulum were present at the opposite, dendritic side of the contact. Some flattened cisterns of granular reticulum were packed into stacks, resembling spine apparatus (Fig. 1A). Single mitochondria were also often present in dendroplasm near desmosome-like contacts. Sometimes such symmetric contacts were observed on the dendrites in the immediate vicinity of the asymmetric chemical contacts. The desmosome-like contacts in the grafted mossy fiber system seemed to be more numerous, and single contacts seemed to have larger dimensions than in the normal hippocampus.

\section{DISCUSSION}

\section{Presynaptic endings of the mossy fibers}

The above data show that the dentate fascia granule cells, grafted into the host barrel field without hippocampal pyramidal cells, or with a minimal admixture of them, gave rise to mossy fibers growing into the host neocortex and ending with typical giant synapses. This was observed in all analyzed tissue samples comprising graft/host astroglial interface and adjacent host neocortical tissue. It should be noted that, in an attempt to use the most rigorous criteria for identification of the host tissue, we selected for analysis the areas separated from the graft by clear glial accumulations, though vast areas of direct confluence of dentate and neocortical neuropil were present in the majority of the grafts $(n=8)$. It is possible that mossy fiber terminals were even more numerous in the neocortex adjacent to such areas, though bundles of mossy fibers can also penetrate the glial interface, as shown by us previously $/ 56 /$.

The terminal synaptic bags of the mossy fibers in the neocortex retained their typical large dimensions. They contained large amounts of densely packed clear round vesicles, as well as a few dense-core vesicles $/ 24,26 /$ and made asymmetric chemical and symmetric desmosomelike contacts with the postsynaptic elements /5,21/. Thus, the ultrastructural features of the giant synapses were preserved and expressed in the host tissue. The desmosome-like contacts and clustering of mitochondria near them seemed to be more prominent in the synapses of dentate grafts than in normal synapses, where mitochondria are more evenly distributed in the synaptoplasm, and the symmetric contacts were more limited. The accumulations of mitochondria on the presynaptic side and cisterns of endoplasmic reticulum on the postsynaptic side of symmetric contacts suggest their probable participation in metabolic interactions. This relative prominence of the desmosome-like contacts may indicate some plastic changes in the mossy fiber synapses depending on unusual targets, or their incomplete ontogenetic development. Some authors have demonstrated that the synapses at an early stage of development resemble desmosomes $12,7 /$. The presence of growth vesicles in some clusters of giant synapses also suggests their continuing growth and development.

\section{Postsynaptic targets of the mossy fibers}

The most specific and typical postsynaptic elements of the terminal mossy fiber synapses in situ were large branched excrescences on the proximal segments of the apical dendritic shafts of large CA3 pyramidal neurons. Such spines were limited only to the area of mossy fiber termination (stratum lucidum) in the hippocampus, and were totally absent from the neocortex. However, the smaller synaptic boutons of the mossy fibers' collaterals made contacts with ordinary smaller spines on the branches of apical dendrites /10/. Some giant boutons had contacts with dendrites, among which were spineless dendrites of the hippocampal nonpyramidal neurons, including basket cells $/ 16,50 /$.

The axonal terminals of the granule cells grafted into the neocortex made contacts with a wide spectrum of elements, from neuronal somata to very thin terminal dendritic branches. It is noteworthy that in those cases where the postsynaptic neurons could be identified (axosomatic giant synapses or contacts upon apical dendrite shafts), they were 
represented by neocortical pyramidal neurons. The origin of smaller dendrites cannot be identified in electron microscopic material.

The dendritic surfaces contacted by the mossy synapses seemed to be in a continuous dynamic state. Probably the various subsynaptic expansions, bumps and large protrusions with greater or smaller accumulations of cytoplasmic organelles, such as polyribosomes, mitochondria, multivesicular bodies, etc., represent various stages of the postsynaptic dendritic modifications under the influence of the mossy terminals. Large, branched spines with relatively normal contents, atypical for neocortex and resembling those in the hippocampal CA3 stratum lucidum, may be regarded as the final stage of such active modification. Accumulation of polyribosomes has been observed in dendritic spines during their induction and growth in ontogenesis $149 /$, regeneration $/ 32,48 /$, and plastic reorganization $/ 21 /$. Both induction of large branched spines in the unusual target neurons (pyramidal cells of the CA1) $/ 41 /$, and accumulation of polyribosomes in the spines $/ 46 /$, have also been described in intrahippocampal dentate grafts. Smaller dendritic branches contacted by the mossy synapses also had abnormally high contents of cytoplasmic organelles. This, together with the presence of dendritic growth tips invaginated by gigantic boutons, suggests induction by the mossy fibers of continuous growth of both dendritic terminal branches and additional protuberances on the larger dendrites.

Some authors, on the basis of experiments with regeneration $/ 8,22,23 /$, have concluded that presynaptic elements may be modified to a great extent by inappropriate postsynaptic targets. Contrary to those views, we did not find any ultrastructural changes of the mossy fiber presynaptic boutons contacting the unusual targets, though induction of growth and modification of cortical postsynaptic elements may be suggested.

\section{Specificity versus non-specificity of connections established by the grafts}

The degree of specificity of connections established by nervous tissue has been investigated in numerous experiments on regeneration in the CNS, in co-cultures of explants of various brain structures, and in homotopic and heterotopic transplants. It is clear that attempts to find factors controlling brain organization during development and regeneration after injury have important theoretical significance and potential practical value. Some authors, using the method of neurotransplantation, have described a high degree of specificity of connections established between the graft and the host brain. The axons of the grafted cells have been described as avoiding inappropriate targets and innervating selectively distant, but appropriate, ones $133,42,53,54 /$. This suggests the action of some tissue-specific biochemical markers controlling propagation of the axons. However, experiments on neuronal regeneration in the early postnatal brain have demonstrated that elimination of the normal target results in the development of aberrant connections with quite unusual brain structures, or in the substitution of the lesioned afferent axons by the remaining afferent and intrinsic fiber systems $/ 14,34,40 /$. In the hippocampal formation, aberrant sprouting after partial deafferentation has been described in adult animals $/ 12,13,28,31,52 /$

Grafting of neocortical tissue into an inappropriate area (e.g., visual cortex into motor area, or cerebellum) had led to the conclusion that both afferent and efferent connections of such grafts are determined primarily by the factor of proximity and reproduce patterns typical of the recipient area of graft placement and not that of the donor tissue $19,15,38,39,43 /$.

The hippocampus, with its layered organization of fiber systems, has been widely used in experiments on specificity of reinnervation. It has been shown, for example, that axons growing from septal cholinergic grafts into the hippocampus, deprived of cholinergic connections, can reproduce a highly specific distribution of cholinergic terminals $14,29 /$. However, the same pattern has also been reproduced by cholinergic cells from other brain structures (brain stem, habenula, caudate) grafted into the denervated hippocampus $/ 1,30 /$. The authors have insisted upon the specificity of developing connections, because the volume of the ingrowing fibers was maximal for the homotopic septal grafts $/ 11,39 /$. However, this finding suggests only relative, not absolute, specificity in control of the development of innervation. It has also been shown that grafting embryonic septal tissue to the 
posterior ridge of the hippocampus reproduces the pattern of cholinergic afferents in the septallydenervated hippocampus. If the septo-hippocampal connections were not interrupted, however, the additional cholinergic fibers from the graft grew aberrantly into the area vacated by the damaged perforant path $/ 3 /$.

Transplants of the dentate fascia into the hippocampus have also been shown to establish, besides the normal connections to $\mathrm{CA} 3$ pyramidal cells, aberrant ones to basal and apical dendrites of the CA1 cells $/ 41,47 /$. Nevertheless, Raisman and Ebner /41/ have insisted on the specificity of this pattern of connections, arguing (i) that the mossy fibers tend to establish contacts close to the CA1 pyramidal cell bodies, and (ii) that mossy fiber-CA1 contacts are present in the hippocampus of some mammals (hedgehogs and Siamese cats /18,27/). These arguments are not completely convincing. Our experimental data show that, though the dentate never has synaptic contacts with neocortical neurons in any animal species, its grafts project mossy axons to neocortical neurons establishing synapses with the ultrastructural features of functional contacts.

Fiber exchange between the graft completely deprived of its own extrinsic connections and the adjacent, damaged recipient brain may be stimulated both by the presence of denervated loci and by production of neurotrophic factors in both tissues $/ 19,25,35 /$. There are also reasons to suggest that the presence within the graft of the natural target neurons, matched in their structural, biochemical and ontogenetic characteristics, may represent a very strong factor, preventing (or limiting) the outgrowth of axons into the surrounding host brain. At least, as was demonstrated in our previous investigations $16,51 /$, the grafts of isolated hippocampus proper seemed to be well integrated with the neocortex by physiological criteria, while the hippocampus grafted together with dentate showed complete functional isolation.

\section{ACKNOWLEDGEMENTS}

The authors would like to thank Dr. A.G. Bragin for preparation of the grafted animals.

\section{REFERENCES}

1. Anderson KJ, Gibbs RB, Cotman CW. Transmitter phenotype is a major determinant in the specificity of synapses formed by cholinergic neurons transplanted to the hippocampus. Neuroscience $1988 ; 25: 19-25$.

2. Babychenko II, Dyachkova LN, Medvedev DJ. Some mechanisms of formation of interneuronal synapses in the vertebrate brain: Electron microscopy study. Proc Acad Sci USSR 1987; 296: 1246-1247 (in Russian).

3. Bjorklund A, Stenevi U. Reformation of the severed septo-hippocampal cholinergic pathway in the adult rat by transplanted septal neurons. Cell Tissue Res 1977; 185: 289-302.

4. Bjorklund A, Nilsson OG, Kalen P. Reafferentation of the subcortically denervated hippocampus as a model for transplant-induced functional recovery in the CNS. Prog Brain Res 1990; 83: 411-427.

5. Blackstad TW, Kjaerheim A. Special axo-dendritic synapses in the hippocampal cortex: Electron and light microscopic studies on the layer of mossy fibers. J Comp Neurol 1961; 117: 133-159.

6. Bragin AG. Morphological and electrophysiological criteria of the degree of integration of the homo- and heterotopic grafts with the host brain. Proc Indian Natl Sci Acad 1990: 1: 59-68.

7. Bogolepov NN, Frumkina LE, Yakovleva NI, Koroleva SK. Presumable mechanisms of synapse formation in ontogenesis. Arch Anat Histol Embryol 1987; 92: 2027 (in Russian).

8. Campbell G, Frost DO. Synaptic organization of anomalous retinal projections to the somatosensory and auditory thalamus: target-controlled morphogenesis of axon terminals and synaptic glomeruli. J Comp Neurol 1988; 272: 383-408.

9. Castro AJ, Hogan TP, Sorensen JC, Klausen BS. Danielsen EH, Zimmer J, Neafsey EJ. Heterotopic neocortical transplants: An anatomical and electrophysiological analysis of host projections to occipital cortical grafts placed into sensorimotor cortical lesions made in newborn rats. Dev Brain Res 1991; 58: 231 236.

10. Claiborne BJ, Amaral DG, Cowan WM. A light and electron microscopic analysis of the mossy fibers of the rat dentate gyrus. J Comp Neurol 1986; 246: 435-458.

11. Clarke DJ, Nilsson OG. Brundin P. Bjorklund A. Synaptic connections formed by grafts of different types of cholinergic neurons in the host hippocampus. Exp Neurol 1990: 107: 11-22.

12. Cook TM, Crutcher KA. Extensive target cell loss during development results in mossy fibers in the regio superior (CA1) of the rat hippocampal formation. Dev Brain Res 1985; 21: 19-30.

13. Davenport CJ, Brown WJ, Babb TL. Sprouting of GABAergic and mossy fiber axons in dentate gyrus following intrahippocampal kainate in the rat. Exp Neurol 1990; 109; 180-190. 
14. Easter SS, Purves D, Rakic P, Spitzer NC. The changing view of neural specificity. Science 1985; 230: 507-511.

15. Floeter MK, Jones EG. Transplantation of fetal postmitotic neurons to rat cortex: survival, early pathway choices and long-term projections of outgrowing axons. Dev Brain Res 1985; 22: 19-38.

16. Frotscher M. Mossy fibers form synapses with identified pyramidal basket cells in the CA3 region of the guinea-pig hippocampus: a combined Golgielectron microscopy study. J Neurocytol 1985; 14: 245 259.

17. Frotscher M. Mossy fibers form synapses on glutamate-decarboxylase-immunoreactive neurons: evidence for feed-forward inhibition in the $\mathrm{CA} 3$ region of the hippocampus. Exp Brain Res 1989; 75: 441-445.

18. Gaarskjaer FB, Danscher G, West MJ. Hippocampal mossy fibers in the regio superior of the European hedgehog. Brain Res 1982; 237: 79-90.

19. Gage FH, Bjorklund A. Denervation-induced enhancement of graft survival and growth. A trophic hypothesis. Ann NY Acad Sci 1987; 495: 378-395.

20. Greenough WT. Experience effects on the developing and the mature brain: dendritic branching and synaptogenesis. In: Krasnegor NA et al., eds, Perinatal Development. Orlando, FL: Academic Press, 1987; 195-221.

21. Hamlyn LH. The fine structure of the mossy fiber endings in the hippocampus of the rabbit. J Anat (Lond) 1962; 96: 112-120.

22. Hamori J, Savy C, Madarasz M, Somogyi J, Takacs J, Vereley R, Farkas-Bargeton E. Morphological alterations in subcortical vibrissae relays following vibrissae follicle destruction at birth in the mouse. $J$ Comp Neurol 1986; 254: 166-183.

23. Hamori J, Takacs J, Vereley R, Petrusz P, FarkasBargeton E. Plasticity of GABA- and glutamatecontaining terminals in the mouse thalamic ventrobasal complex deprived of vibrissae afferents: an immunogold-electron microscopic study. J Comp Neurol 1990; 30: 739-748.

24. Ibata Y, Otsuka N. Fine structure of synapses in the hippocampus of the rabbit with special reference to dark presynaptic endings. Z Zellforsch 1968; 91: 547 553.

25. Ishikawa R, Nishikori K, Furukawa S. Appearance of nervous growth factor and acidic fibroblast growth factor with different time courses in the cavity-lesioned cortex of the rat brain. Neurosci Lett 1991; 127: 70-72.

26. Laatsch RH, Cowan WM. Electron microscopic studies of the dentate gyrus of the rat. I. Normal structure with special reference to synaptic organization. J Comp Neurol 1966; 128: 359-368.

27. Laurberg S, Zimmer J. Aberrant hippocampal mossy fibers in cats. Brain Res 1980; 188: 555-559.

28. Laurberg S, Zimmer J. Lesion-induced sprouting of hippocampal mossy fiber collaterals to the fascia dentata in developing and adult rats. J Comp Neurol 1981; 200: 433-459.

29. Letvis ER, Cotman CW. Mechanisms of septal lamination in the developing hippocampus revealed by outgrowth of fibers from septal implants. I. Positional and temporal factors. Brain Res 1980; 196: 307-330.

30. Lewis ER, Cotman CW. Neurotransmitter characteristics of brain grafts: striatal and septal tissues form the same laminated input to the hippocampus. Neuroscience 1983; 8: 57-66.

31. Lynch G, Matthews DA, Mosko S, Parks T, Cotman DA. Induced acetylcholinesterase-rich layer in rat dentate gyrus following entorhinal lesions. Brain Res 1972; 42: 311-318.

32. McWilliams JR, Lynch G. Terminal proliferation and synaptogenesis following partial deafferentation. The reinnervation of the inner molecular layer of the dentate gyrus following removal of its commissural afferents. J Comp Neurol 1978; 180: 581-616.

33. Mathews MA. Transplantation of fetal lateral geniculate nucleus to the occipital cortex: connectivity with host's area 17. Exp Brain Res 1985; 58: 473-489.

34. Metin C, Frost DO. Visual responses of neurons in somatosensory cortex of hamsters with experimentally induced retinal projections to somatosensory thalamus. Proc Natl Acad Science USA 1989; 86: 357-361.

35. Needels DL, Nieto-Sampedro $\mathrm{M}$, Cotman $\mathrm{CW}$. Induction of a neurite-promoting factor in rat brain following injury or deafferentation. Neuroscience 1986; 18: 517-526.

36. Niklowitz W. Electronenmikroskopische Untersuchungen am Ammonshorn. III. Vergleichende phasenkontrast- und electronen-mikroskopische Darstellung der Moosfaserschicht. Z Zellforsch 1966; 75: 485-500.

37. Nilsson OG, Clarke DJ, Brundin P, Bjorklund A. Comparison of growth and reinnervation properties of cholinergic neurons from different brain regions grafted to the hippocampus. J Comp Neurol 1988; 268: 204-222.

38. Oblinger MM, Das GD. Connectivity of neural transplants in adult rats: analysis of afferents and efferents of neocortical transplants in the cerebellar hemisphere. Brain Res 1982: 249: 31-49.

39. O'Leary DDM, Stanfield BB. Selective elimination of axons extended by developing cortical neurons is dependent on regional locale: experiments utilizing fetal cortical transplants. J Neurosci 1989; 9: 22302246.

40. Pallas SL, Roe AW, Sur M. Visual projections induced into the auditory pathways of ferrets. I. Novel inputs to primary auditory cortex (AI) from the LP/pulvinar complex and the topography of the medial geniculate nucleus-AI projection. J Comp Neurol 1990: 298: 5068. 
41. Raisman G, Ebner FF. Mossy fiber projections into and out of hippocampal transplants. Neuroscience 1983; 9: 783-801.

42. Raisman G, Morris RJ, Zhou CF. Specificity in the reinnervation of adult hippocampus by embryonic hippocampal transplants. Prog Brain Res 1987; 71: 325-333.

43. Santacana M, Heredia $M$, Valverde F. Transplant connectivity in the rat cerebral cortex. A carbocyanine study. Dev Brain Res 1990; 56: 217-222.

44. Segal M. Interactions between grafted serotonin neurons and adult host rat hippocampus. Ann NY Acad Sci 1987; 495: 284-294.

45. Singer J. Recovery mechanisms in the mammalian brain. In: Nicholls JG, ed, Repair and Regeneration of the Nervous System. Berlin: Springer-Verlag, 1982; 203-226.

46. Sorenson T, Zimmer J. Ultrastructural organization of normal and transplanted rat intraocular grafts: I. A qualitative analysis of intracerebral and intraocular grafts. J Comp Neurol 1988; 267: 15-42.

47. Sorensen T, Zimmer J. Ultrastructural organization of normal and transplanted rat fascia dentata: II. A quantitative analysis of the synaptic organization of intracerebral and intraocular grafts. J Comp Neurol 1988; 267: 43-54.

48. Steward O. Lesion-induced synapse growth in the hippocampus. In search of cellular and molecular mechanisms. In: Isaacson RL, Pribram KH, eds, The Hippocampus. New York, NY: Plenum Press, 1986; vol. 3: 65-111.

49. Steward O. Regulation of synaptogenesis through the local synthesis of protein at the postsynaptic site. Prog Brain Res 1987; 71: 267-279.

50. Tombol T, Somogyi F, Hajdu F, Madarasz M. Granule cells, mossy fibers and pyramidal neurons: an electron microscopic study of the cat's hippocampal formation. I. Acta morphol Hung 1978; 26: 291-310.

51. Vinogradova OS, Bragin AG, Kitchigina VF. Spontaneous and evoked activity of the neurons in the intrabrain allo- and xenografts of the hippocampus and septum. In: Bjorklund A, Stenevi U, eds, Transplantation in Mammalian CNS. Elsevier, 1985; 409-419.

52. West JR, Dewey SL. Mossy fiber sprouting in the fascia dentata after unilateral lesions: quantitative analysis using computer-assisted image processing. Neuroscience 1984; 13: 377-384.

53. Wictorin K, Clarke DJ, Bolam JP, Brundin P, Gustavii B, Lindvall O, Bjorklund A. Extensive efferent projections of intra-striatally transplanted striatal neurons as revealed by a species-specific neurofilament marker and anterograde axonal tracing. Prog Brain Res 1990; 82: 391-399.

54. Zhou CF, Li Y, Raisman G. Embryonic entorhinal transplants project selectively to the deafferented entorhinal zone of adult mouse hippocampus, as demonstrated by the use of Thy-1 allelic immunohistochemistry. Effect of timing of transplantation in relation to deafferentation. Neuroscience 1989; 32: 349-362.

55. Zhuravleva ZN. Ultrastructural investigation of the hippocampal synapses. In: Budantsev AY, ed, Neurochemistry and Physiology of Synaptic Transmission. Puschino, 1976; 116-142 (in Russian).

56. Zhuravleva $\mathrm{ZN}$. Intracortical dentate fascia grafts in the adult rat hosts. Ultrastructure of the graft/host interface. J Hirnforsch 1991; 32: 384-397.

57. Zimmer J. Proximity as a factor in the regulation of aberrant axonal growth in postnatally deafferented fascia dentata. Brain Res 1974; 72: 137-142. 

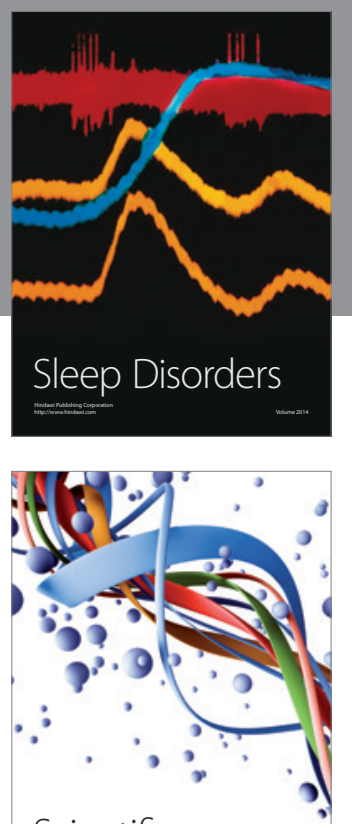

Scientifica
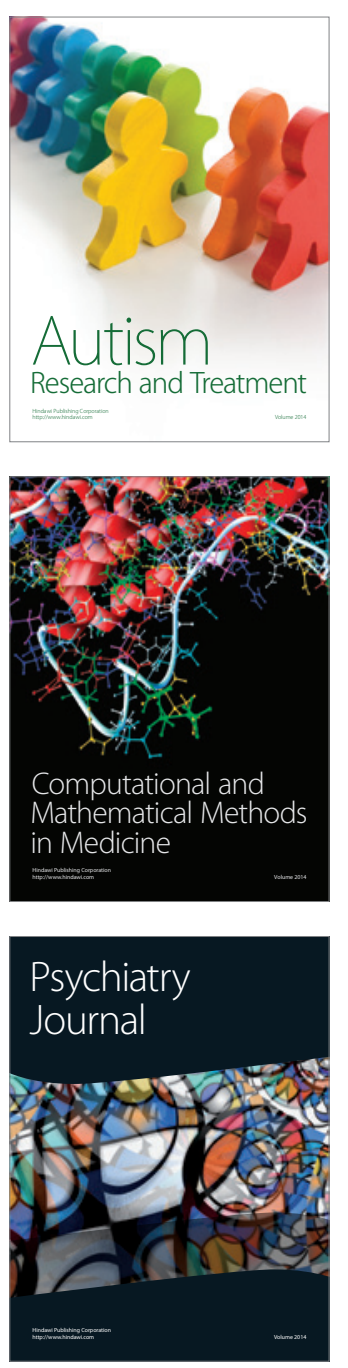
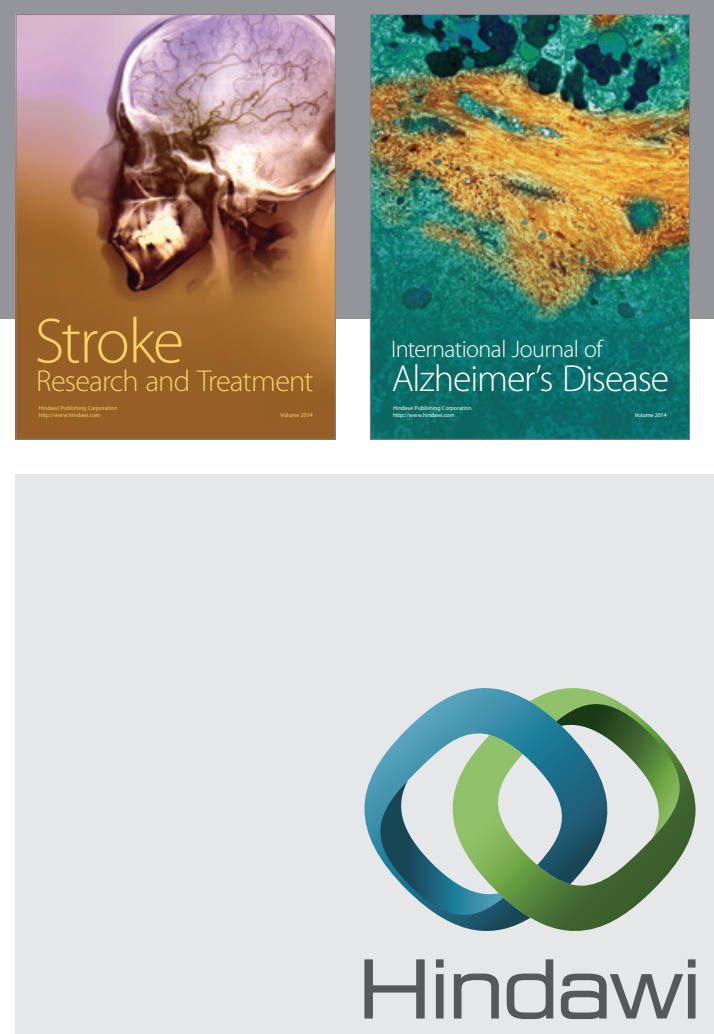

Submit your manuscripts at

http://www.hindawi.com
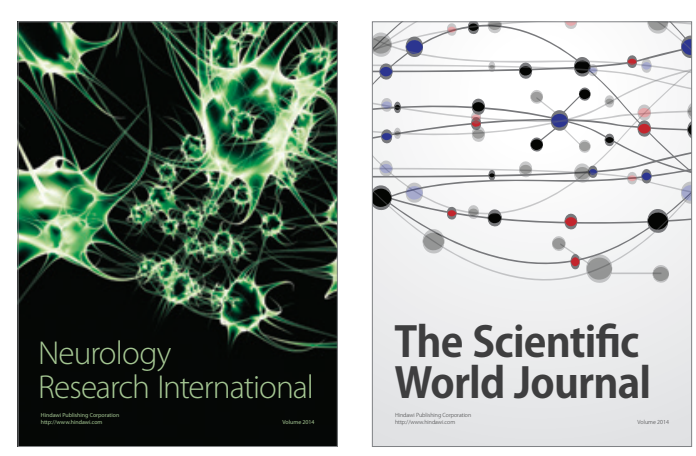

The Scientific World Journal

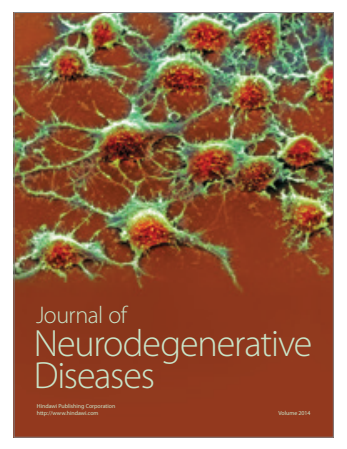

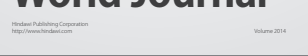

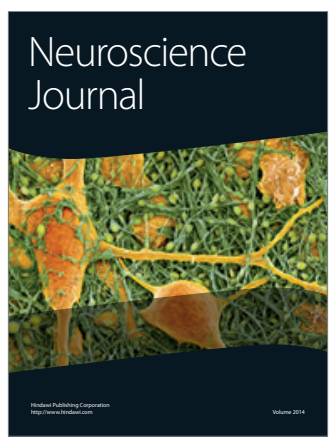

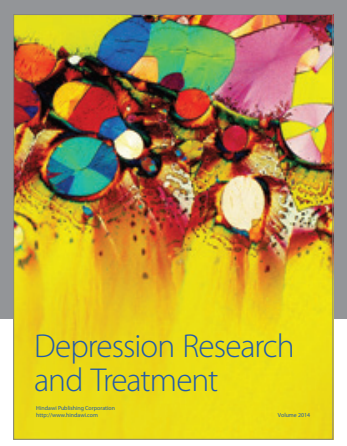
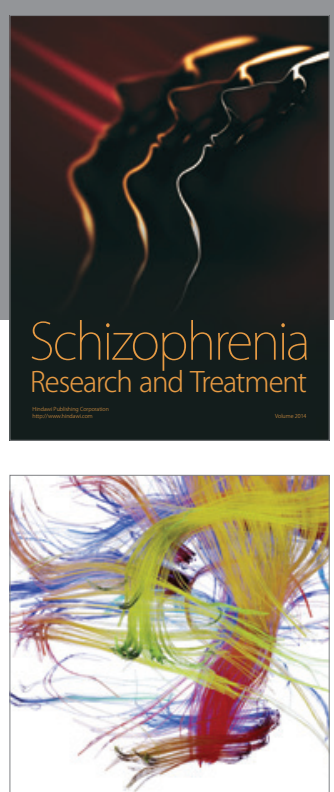

Brain Science

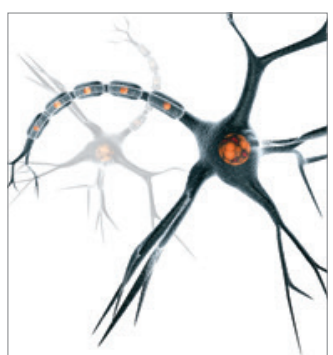

Neural Plasticity
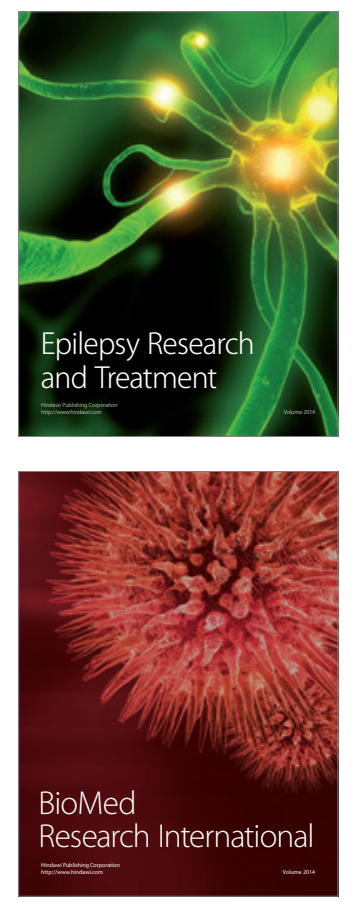

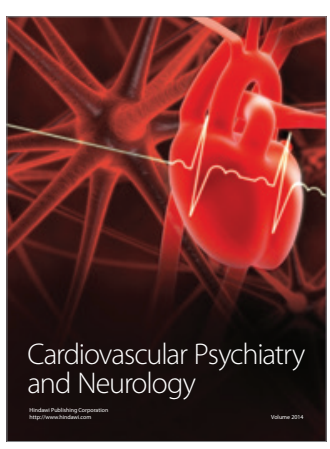

Parkinson's

Disease
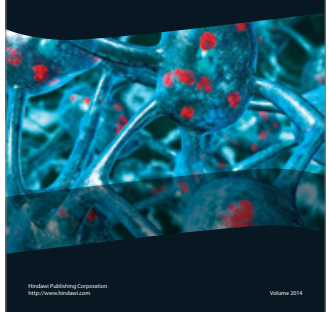